\title{
Towards a deeper understanding of how champions influence the allocation of resources to innovation projects
}

\author{
Maarten E.J. Rutten*1, Andre G. Doree ${ }^{2}$, and Johannes I.M. Halman ${ }^{2}$
}

\begin{abstract}
Previous research indicates that the presence of a champion in an innovation project increases the likelihood that firms will allocate resources to the innovation project. Relatively little is, however, known about how champions' presence exactly influences resource allocation. A case study of two innovation projects in the construction industry was conducted to further explore this question. The findings suggest that it is not so much champions' presence as such, but one of champions' prototypical behaviours that influences firms' willingness to allocate resources. Here we refer to champions' expression of enthusiasm and confidence about the success of an innovation. Further, the findings suggests that the effect might be explained by the mediating role of firms' expectations of the rate of adoption. Overall, the case study provides a step towards a deeper understanding of how champions induce firms to allocate resources to innovation projects.
\end{abstract}

\section{Keywords}

champions, innovation, resource allocation

\footnotetext{
${ }^{1}$ School of Built Environment, Avans University of Applied Sciences, P.O. Box 732, 5201AS 'sHertogenbosch, Netherlands mej.rutten@avans.nl* Corresponding author

${ }^{2}$ Department of Construction Management and Engineering, University of Twente, PO Box 217 7500AE Enschede, Netherlands
} 


\section{Introduction}

The role of champions was first discussed in an article by Schon (1963) on the development of innovations. Schon argued that the successful development of a new product idea requires the presence of a champion. As he put it: 'the new idea either finds a champion or dies.' In his article, champions are characterized as individuals 'who identify with the idea as their own, and with its promotion as a cause, to a degree that goes far beyond the requirements of their job (Schön, 1963: 84-85).' These and other early studies on champions (Chakrabarti, 1974, Rothwell et al, 1974) stimulated a wide range of researchers to study the role of champions. The first studies on the role of champions in the construction industry are from the 1980s and 1990s (Tatum, 1984; Nam et al., 1991; Nam and Tatum, 1997). New studies in this field are continuing to increase our understanding of the role of champions (Toole et al., 2013; Sergeeva, 2014; Herazo and Lizarralde, 2015; Shibeika and Harty, 2015).

The effect that has received the most attention from construction management researchers is that of champions on the innovativeness of construction projects (Tatum, 1984; Nam et al., 1991; Nam and Tatum, 1997; Barlow, 2000; Bossink, 2004; Dulaimi et al., 2005; Gambatese and Hallowell, 2011a). Other effects studied in this field include the effects of champions on the extent to which technical innovations diffuse within the construction industry (Gambatese and Hallowell, 2011b), on the social outcomes of 'Percent for Art' projects (McCabe et al., 2011) and on the performance of technology development projects in road infrastructure (Caerteling et al., 2009). The present study focuses on a champion effect that has been found in other industries, such as the aeronautics and space industry, the steel industry and the chemical industry (Chakrabarti, 1974; Markham et al., 1991; Markham, 2000), but that has remained unexplored in the construction industry. Here we refer to the effect of champions on the allocation of resources, i.e. budget, personnel or facilities, to innovation projects. (It should be noted that innovation projects and construction projects represent two types of projects. As Bosch-Sijtsema and Postma (2009) explain in their study on innovation in projectbased industries, construction projects are projects executed by order of a specific client whereas innovation projects aim at technology development or innovation and take place separately from construction projects.)

Studies conducted by Chakrabarti (1974), Markham et al. (1991) and Markham (2000) indicate that the presence of a champion in an innovation project makes it more likely that resources will be allocated to the innovation project. It has been argued in recent literature that champions' advocacy behaviour may explain this effect (Schlapp et al., 2015). A deeper understanding of how champions influence resource allocation is, however, lacking. Therefore, the present study aims to contribute to the understanding of how champions' presence affects resource allocation. We do so by drawing on a case study of two collaborative innovation projects from the Dutch construction industry. The term 'collaborative innovation project' refers to innovation projects in which firms join forces to cooperate in the development and commercialization of a new building product or system that is not specifically developed for a single construction project, but for a range of potential future construction projects. (This definition is based on the definition of an innovation project offered by BlindenbachDriessen et al (2010: 577).) Previous literature provides various examples of collaborative innovation projects from the construction industry. Such as the joint development and commercialization of a new modular housing system by a group of firms as described by Hofman et al. (2009), and the joint development and commercialization of a new floor system as described by Bosch-Sijtsema and Postma (2009).

\section{Previous Research on Champions}

Roughly ten years after Schon (1963) had argued that champions have an important role in innovation, a study of 43 innovation pairs provided support for Schon's claim (Rothwell et al., 1974). 
That study, entitled project SAPPHO, was designed to discover differences between successful and unsuccessful innovations. The study's findings indicated that the presence of a champion was positively related to the commercial success of an innovation. The study defined the presence of a champion as the presence of 'any individual who made a decisive contribution to the innovation by actively and enthusiastically promoting its progress through critical stages' (Rothwell et al., 1974: 291). In the same year, the results of another study on the role of champions, based on an assessment of 45 NASA innovations, were also published (Chakrabarti, 1974). Here, Chakrabarti argued that the presence of a champion increases the likelihood that a new product idea is actually developed into a new product that is then marketed. Further, he argued that the important role of the champion in the development of a new product lies in 'selling the idea to management and getting the management sufficiently interested in the project'. Together, the articles by Schon (1963), Rothwell et al. (1974) and Chakrabarti (1974) represent widely cited early work on the role of champions in innovation.

It is important to note that whereas the early work characterizes champions as heroes of innovation, later work provides a more balanced view (Schilling, 2010). For example, more recent work also suggests that champions sometimes want to go too fast in the beginning of an innovation project (Boersma, 1994), or may ignore important negative information and persist in the mistaken belief that their ideas will be successful (Walter et $a l ., 2011)$. In addition, it has been suggested that firms may benefit from cultivating so-called 'antichampions' or 'exit-champions', i.e. individuals who play the role of devil's advocate, to counter the risks of champions' behaviour (Devaney, 1991; Royer, 2003).

\section{Champions' Behaviour}

The importance attributed to the role of champions in innovation, as articulated in the early literature, has inspired researchers, both in the construction industry and in other industries, to further explore what it is that characterizes champions. For example, based on a study of 28 information technology innovations, Howell and
Higgins (1990) argue that champions exhibit transformational leadership behaviours (inspiration, intellectual stimulation and charisma) to a greater extent than non-champions, that they display greater achievement, risk taking and innovativeness than non-champions and that they make more attempts to influence and use a greater variety of influence tactics than non-champions. In addition, based on the same study, Howell and Boies (2004) argue that champions provide more enthusiastic support for new ideas than nonchampions, that they more often tie the innovation to a greater range of positive organizational outcomes than non-champions and that they use informal selling processes more often than nonchampions. Based on a study of ten innovative construction projects, Nam and Tatum (1997) argue that, in the construction industry, champions usually occupy senior managerial positions and possess technical competence. Overall, a characteristic that has sparked discussion is the capacity of champions to influence others (Howell and Higgins, 1990). A study of eight champions in the UK facility management sector (Leiringer and Cardellino, 2008) contributed to this discussion by concluding that champions seem to influence others by using rhetorical strategies.

Taken together, these studies have contributed to identifying behaviours that characterize champions. However, a related question that remained unanswered for quite some time was which behaviours best characterize champions? In other words, which behaviours are prototypical of champions? A study by Howell et al (2005) provided the first rigorous attempt to answer this question. The study was designed to develop and validate a measure of champion behaviour. It involved champions from various industries and consisted of three empirical phases. In an initial study, a list of 102 different champion behaviours was generated. Subsequently, the prototypicality of each of these behaviours was examined through a second study that led to the identification of 29 champion behaviours that appeared 'to represent the core of the domain of championship' (for an overview see Howell et al., 2005: 649). Finally, the results of a third study indicated that the 29 champion behaviours reflected three core behaviours: (1) expressing enthusiasm and confidence about the success of the innovation; (2) 
Table 1: Studies in the construction industry on the effect of champions on the innovativeness of a construction project

\begin{tabular}{|c|c|}
\hline Study & Findings \\
\hline $\begin{array}{l}\text { Six innovative US construction } \\
\text { projects (Tatum, 1984) }\end{array}$ & $\begin{array}{l}\text { In each of the innovative construction projects there was an } \\
\text { energetic individual in the planning team willing to serve as a } \\
\text { champion for the proposed innovation. }\end{array}$ \\
\hline $\begin{array}{l}\text { One innovative US construction } \\
\text { project (Nam et al., 1991) }\end{array}$ & $\begin{array}{l}\text { Various individuals in the innovative project exhibited } \\
\text { champion behaviour; including the structural designer, } \\
\text { concrete supplier, owner, material consultant and the } \\
\text { contractor's consultant. }\end{array}$ \\
\hline $\begin{array}{l}\text { Ten innovative US construction } \\
\text { projects (Nam and Tatum, 1997) }\end{array}$ & $\begin{array}{l}\text { In many of the cases in this study, it seemed likely that the } \\
\text { absence of one specific individual would have prevented or } \\
\text { delayed innovation success. These individuals were described } \\
\text { as champions by other professionals involved in the project, } \\
\text { and most of them possessed both power and technical } \\
\text { competence. }\end{array}$ \\
\hline $\begin{array}{l}\text { One innovative UK construction } \\
\text { project (Barlow, 2000) }\end{array}$ & $\begin{array}{l}\text { The presence of champions contributed to project } \\
\text { innovativeness. Each of the main partners had an identifiable } \\
\text { individual providing support and selling the innovative } \\
\text { partnering concept to senior executives within their own } \\
\text { organization. }\end{array}$ \\
\hline $\begin{array}{l}\text { Ten innovative Dutch } \\
\text { construction projects (Bossink, } \\
\text { 2004) }\end{array}$ & $\begin{array}{l}\text { Each of the innovative projects had two or three champions } \\
\text { who acted as driving forces behind the initiation and } \\
\text { realization of innovative ideas. }\end{array}$ \\
\hline $\begin{array}{l}32 \text { Singapore construction } \\
\text { projects (Dulaimi et al., 2005) }\end{array}$ & $\begin{array}{l}\text { Statistical analysis showed no significant relationship between } \\
\text { championing behaviour as exhibited by the project manager } \\
\text { and the innovativeness of the project. }\end{array}$ \\
\hline $\begin{array}{l}\text { Ten US construction projects } \\
\text { (Gambatese and Hallowell, } \\
\text { 2011a) }\end{array}$ & $\begin{array}{l}\text { The results showed a positive relationship between the extent } \\
\text { to which there was a champion, shepherding the innovation } \\
\text { and eliminating potential blocks, and project innovativeness. }\end{array}$ \\
\hline
\end{tabular}

persisting under adversity; and (3) getting the right people involved. Thus, according to this study, these three behaviours are prototypical of champions across industries.

\section{Effects of Champions}

Besides studying the behaviour of champions, researchers have also studied the effects that champions have. Although the champion concept gained rapid popularity, there was still little empirical evidence at the start of the 1990s as to the effects of champions (Markham et al., 1991). However, since then, empirical evidence on the effects of champions has grown steadily. This includes empirical studies of champions in the construction industry (Nam et al., 1991; Nam and Tatum, 1997; Barlow, 2000; Bossink, 2004; Dulaimi et al., 2005; Caerteling et al., 2009; Gambatese and Hallowell, 2011a; Gambatese and Hallowell, 2011b; McCabe et al., 2011) and in other industries (Markham et al., 1991; Day, 1994; Markham, 1998; Markham and Griffin, 1998; Andersson and Bateman, 2000; Howell and Shea, 2001; Howell and Shea, 2006; Lichtenthaler and Ernst, 2009; Walter et al., 2011). Tables 1 and 2 summarize the findings from the construction 
Table 2: Studies in the construction industry on other effects of champions

\begin{tabular}{ll}
\hline Study & Findings \\
\hline $\begin{array}{l}115 \text { technology development } \\
\text { projects by US road } \\
\text { infrastructure firms (Caerteling et } \\
\text { al., 2009) }\end{array}$ & $\begin{array}{l}\text { The results show a positive relationship between championing } \\
\text { behaviour exhibited by government officials and both the } \\
\text { process performance of the technology development project } \\
\text { (in terms of budget, quality and development time) and the } \\
\text { benefits of the technology to customers. }\end{array}$ \\
$\begin{array}{l}\text { Three-quarters of the respondents rated champion presence as } \\
\text { innovations (Gambatese and } \\
\text { Hallowell, 2011b) }\end{array}$ & $\begin{array}{l}\text { an enabler in implementing their innovative product in } \\
\text { projects. However, statistical analysis showed no significant } \\
\text { relationship between champion presence and the extent to } \\
\text { which the innovative product had diffused throughout the } \\
\text { industry. }\end{array}$ \\
$\begin{array}{l}\text { Four Australian 'Percent for Art' } \\
\text { projects (McCabe } \text { et al., 2011) }\end{array}$ & $\begin{array}{l}\text { The presence of champions within the Artwork Selection } \\
\text { Committees contributed to the social outcomes of the 'Percent } \\
\text { for Art' projects. }\end{array}$
\end{tabular}

Note: the dependent variables studied are shown in italics.

industry studies on the effects champions have on the innovativeness of a construction project (Table 1) and on other variables (Table 2 ).

For studies of the effect of champions on resource allocation to innovation projects, we have to turn to studies conducted in other industries. The effect of champions on the allocation of resources to innovation projects has been studied in two studies in other industries. The first study is the one already mentioned into 45 NASA innovations (Chakrabarti, 1974). The results showed that the presence of a champion in an innovation project made it more likely that, after technical feasibility testing, additional resources would be allocated to start marketing the new product. A later study of 213 innovation projects found similar results (Markham et al., 1991; Markham, 2000). This later study examined innovation projects in various industries: steel; agricultural chemicals and pesticides; packaged processed foods; and industrial chemicals. Further, the study focused on a specific phase of innovation projects: from the moment of formally committing resources to the innovation project to the moment that the $R \& D$ department transferred the new product to another department for commercialization. The results showed that, during this phase, the presence of a champion made it more likely that additional resources would be allocated to the project. Overall, both studies suggest that champions' presence makes it more likely that resources will be allocated to an innovation project. Figure 1 displays the effect that was found in previous research and that represents the focus of the present study.

Relatively little is, however, known about how champions' presence exactly affects resource allocation. A study by Markham (1998) examined whether champions' use of cooperative and confrontational tactics increases decision-makers' willingness to participate in an innovation project. The results indicated that neither champions' use of cooperative nor confrontational tactics increases the likelihood of resource allocation. In response to the results, Markham argued that future research should address the mechanism by which champions affect resource allocation. In recent literature it is argued that champions' advocacy behaviour plays an important role in managers' project funding decisions (Schlapp et al., 2015). A deeper understanding of how champions' presence exactly influences resource allocation is, however, still lacking. The case study presented here provides a step towards such deeper understanding. 
participated in the two collaborative innovation projects.

\section{Data Sources}

To collect data, we conducted interviews and examined documents. In total, we conducted 20 interviews varying in length from 50 to 160 minutes, with an average duration of 90 minutes. Interviewees were selected who had been participating in the innovation projects and who were expected to be able to provide relevant information about the topic under study. We interviewed 21 people in total from 17 firms (one person was interviewed twice and two interviews included two informants). The interviews for the RHC project covered eight firms that had invested resources in the innovation project. The interviewees for the EFW project came from five firms that had invested resources in the innovation project plus three firms that had been involved in the innovation project in other roles and one client who had adopted the new product.

We conducted semi-structured interviews to allow ourselves the opportunity to probe deeper into informants' perceptions and to address informant-specific topics. Besides asking questions about how firms had become involved in the innovation projects, their motivation, the activities undertaken, and resources invested, we also asked questions about the role of the champions. We recorded and transcribed all the interviews. Besides

Table 3: Firms that participated in the collaborative innovation projects

\begin{tabular}{ll}
\hline RHC innovation project & EFW innovation project \\
\hline Architecture firm & Maintenance contractor \\
Bank & Manufacturers of windows \\
Environmental engineering firm & Suppliers of coatings \\
Straw-bale building firm & Supplier of wood \\
Supplier of wall heating systems & Supplier of sills \\
Structural engineering firm & Supplier of sealants \\
Property developers & Supplier of glass \\
Manufacturer of wooden walls & Supplier of fasteners, aluminium profiles and ventilation \\
Manufacturer of wooden floors & systems \\
Innovation consultancy firm & Technology development firm \\
Construction firm & \\
Various other firms & \\
\hline
\end{tabular}


conducting interviews, we collected documents such as internal memos, minutes, e-mails, brochures, newsletters, newspaper articles, magazine articles, product specifications and a product handbook. The document collection process involved asking informants if they could provide documents that illustrated their statements or that they thought that would be of interest to us. We also performed an internet search to retrieve additional information. In total, we collected 31 documents containing information about the RHC project and 38 documents containing information about the EFW project. To facilitate data analysis and enhance the reliability of the case study, the interview transcripts and documents were imported into qualitative data analysis software (NVIVO 9).

\section{Data Analysis}

We used Figure 1, i.e. the figure of the effect we aim to explain, as a framework to examine the case study data. We did so by applying a process outlined by Eisenhardt (1989). From the case study data, we induced tentative constructs and propositions that might potentially explain the effect depicted in Figure 1. We did so by first searching for recurring themes and patterns of relationships in the data from the EFW project. Subsequently we analysed the data from the RHC project in the same way and also searched for similarities and differences between the two collaborative innovation projects. Further, we compared the tentative constructs and propositions that emerged from the case study data with existing literature; which contributed to construct validity. We then kept iterating between the data, propositions, and existing literature until we reached, what Eisenhardt (1989) calls, theoretical saturation. According to Yin (2014) this iterative way of explanation building contributes to the internal validity of case studies. The complete process resulted in two propositions that provide an explanation for how champions' presence affects resource allocation.

\section{The Collaborative Innovation Projects}

Drawing on the case study data, we provide an overview of the two collaborative innovation projects in this section. We first describe the Renewable Housing Concept (RHC) project, and then the Environmentally Friendly Window (EFW) project.

\section{The RHC Project}

The RHC project was initiated by a group of four firms: a bank, an environmental engineering firm, a straw-bale building firm and an architecture firm. During a conference on the use of renewable materials in construction, a manager from the bank had met the owners of the environmental engineering firm and the straw-bale building firm. They had realized that they shared a vision of the future. The idea formed to develop a new type of renewable house. However, they needed help from other types of firms to realize this vision. As the manager from the bank noted, '... to really develop a house you need more than only philosophers, you also need a heating installer, a manufacturer of windows, a foundations worker and an architect.'

Soon after, a partner of an architecture firm who shared the same vision, and who had considerable experience in designing timberframed houses, linked up with the three firms. (Later in the article this person will be identified as the champion for the new renewable housing concept.) Together they set up an innovation project to develop a new system for the construction of renewable houses. The renewable houses should have three characteristics. First, the houses should be characterized by a very high use of renewable materials with the use of nonrenewable materials kept to a minimum. Second, the houses should be cheaper than conventional houses so that they would be affordable to large parts of society. Third, compared to standard houses, the houses should provide a healthier environment.

From that moment on, various other firms joined the innovation project. The partner in the architecture firm (referred to as Anderson) was particularly successful in making other firms enthusiastic about joining the innovation project. 
Since it was decided that the houses should be timber-framed, the first firm that was invited to join the innovation project was a structural engineering firm that specialized in wood constructions. As a manager of the structural engineering firm described it, "At a certain point someone has an idea and says, "What do you think about this?", and then you start. That was Anderson.' A second firm that Anderson invited to join the innovation project was a manufacturer of wooden floors: 'At a certain moment, Anderson had an idea about a way of building in which he got other organizations involved, like us.' Further, a third firm, a supplier of wall heating systems, joined the innovation project: 'We are innovative so when the question of how to use a low temperature heating system given the wooden floor system was put to us, we owed it to ourselves to think about how to do this.' Once they decided to join the innovation project, all three firms contributed to the development of the renewable house concept by investing resources in specific development activities. The structural engineering firm contributed by developing a structural design for the building system. The manufacturer of wooden floors contributed by developing a wooden floor system and, similarly, the supplier of wall heating systems developed a wall heating system. For all these firms, as well as for the four firms that had initiated the innovation project, the time and money spent was from their own accounts. The hope was that these investments would pay off in the future through the construction of houses. As one of the interviewees explained, '...investment of time in development is at your own risk, you hope there will be construction projects - that is the approach.' In addition to the firms already mentioned, a supplier of insulation material made from sheep's wool and a supplier of cabling for houses also joined the innovation project.

About a year after the start of the development of the new renewable housing concept it was launched at a meeting, followed by presentations across the country. The launch event and presentations were attended by social housing corporations, property developers and municipalities. In the years after the launch event, more firms joined the innovation project. These included property developers, a construction firm, an engineering firm, an innovation consultancy firm and various suppliers of construction materials and components. The ways in which these firms became involved in the innovation project varied. Some were invited to join by one of the already participating firms. For example, by the partner in the architecture firm: 'At a certain moment I was invited by Anderson, he is one of the initiators.' Otherwise a firm might become aware of the innovation project, and subsequently contact one of the participating firms. This occurred, for example, after having attended the launch event: 'I did not know Anderson, we met him over there, and that is where the enthusiasm came from.'

\section{The EFW Project}

The EFW project was initiated by a technology development firm and two other companies. Since the technology development firm's start-up in the 1980s, it had gained extensive knowledge on how to repair and prevent rot and decay in wooden window frames. Based on this knowledge, the firm had already developed various products in the past. These products were distributed and sold using a network of licensees made up of various maintenance contractors and window manufacturers. Several trends inspired the technology development firm to develop a new type of environmentally friendly window that would better fit with evolving customer needs. A manager of the technology development firm, together with the director of a maintenance contracting firm and a director of a window manufacturing firm, created a plan to develop the new type of window. (Later in the article these individuals will be identified as the champions for this new environmentally friendly window.) The idea was to develop a high-quality wooden window frame that would be environmentally friendly and require little maintenance. Further, the idea was to offer certainty and single-point responsibility with regard to low overall purchase cost and maintenance. To realize the new product idea, the cooperation of other firms was needed. As one of the initiators explained: 'Then we said, if we are going to do this, then we really have to think in terms of the system, set up an integrated supply chain approach and get manufacturers of wooden windows involved, a supplier of wood, a supplier of glass etc.' After several meetings, the initiators 
obtained commitment from seven suppliers: a supplier of glass; a supplier of wood; two suppliers of coatings; a supplier of fasteners, aluminium profiles and ventilation systems; a supplier of sills; and a supplier of sealants. Together, these seven suppliers covered nearly all the components and materials that would be needed to construct the environmentally friendly window. Once the suppliers had decided to invest resources in the innovation project, various development and commercialization activities were started. These included activities such as developing and testing the window, developing a quality guarantee system and developing a marketing strategy and related tools. Later, another window manufacturer joined the innovation project, bringing in experience with a new mounting system for windows.

About a year after the start of the development of the new product, the new product was launched during a conference organized by the technology development firm. As one of the interviewees noted, 'We rented the whole place, invited all our clients, and really launched it.' In the next few years, further commercialization activities took place to stimulate adoption of the new product.
These included all kinds of marketing activities, including the development of additional marketing tools, enlarging the distribution network by licensing other window manufacturers to produce and sell the product and the setting up of technical and sales courses for licensees.

\section{The Pattern that Emerged}

In this section, we discuss how in both innovation projects champion presence might have influenced firms' willingness to allocate resources. We end this section by presenting a model that reflects the cross-case pattern that emerged from the case study data.

As the descriptions of the two collaborative innovation projects show, both projects were initiated by directors and managers from more than one firm. Among these directors and managers there were several individuals who, based on the three core behaviours of champions (see Howell et al., 2005), were classified as champions. In the RHC innovation project it was the partner in the architecture firm (referred to as

Table 4: Examples of the type of remarks from which the propositions were derived Remarks by firms that participated in the innovation projects

Firm A: 'Then someone says something. And then you start developing. That was Anderson.'; 'He wanted to set it up. He thought there is a market for it.'; 'Investment of time in development is at your own risk, you hope there will be construction projects, that is the approach.'

Firm B: 'And then he asked us to develop a wall heating system. And told me more about the concept. He was very enthusiastic. That inspired me.'

Firm C: 'I did not knew Anderson, we met him over there, and that is where the enthusiasm came from.'; 'He is capable of making an inspiring story of it. He puts his heart into it. That is his quality.'

Firm D: 'He is a man who can create enthusiasm among others. He got a lot of people enthusiastic about this innovation project, including us.'; 'In one of the first meetings we were asked to allocate resources. We saw it as an opportunity since it is a concept in which we believe.'; 'In the beginning you hear stories about the number of future construction projects'; 'It is an idea, originating from him. He had an idea about a system. You have a meeting with him. Then you become more and more enthusiastic. Then you develop a system.'

Firm E: 'We all thought the adoption would go faster.'; 'He very much believes in what he is doing and is very good at communicating it to others.'

Firm F: 'The other side of the story is that they, I think, presented it convincingly. This has a good chance. The timing is right, so join now because you too can profit.' 
Anderson): 'He really is the driving force..., if Anderson falls away, I think the whole thing will collapse.' In the EFW innovation project there were three individuals who particularly displayed champion behaviour. First, there was a manager of the technology development firm: 'Really, I just believe in it. I do not believe that people will still want other windows.' Second, a director of the window manufacturing firm (referred to as Jones): 'In the beginning it was Jones, he really was a driving force. He still is. Yes, absolutely. He is full of energy.' Third, the director of the maintenance contracting firm (referred to as Lewis): 'He really is a driving force, Lewis.' It were these individuals, in both innovation projects, who had an important role in getting other firms involved. As one of the interviewees said about the involvement of other firms in the RHC innovation project: 'Anderson has been the person who got other organizations involved.' Similarly, the manager of the technology development firm said regarding the meetings with suppliers that led to their involvement in the ESW project: 'That is how we got those seven suppliers involved. We had these meetings together with Jones and Lewis.'

The combination of various remarks made by firms we interviewed, elucidates how champions' presence might have influenced firms' willingness to allocate resources to the innovation projects; examples of such remarks are provided in Table 4. First, the case study data indicate that it is one of champions' prototypical behaviours, rather than their presence, that influenced firms' willingness to allocate resources to the innovation projects. Here we refer to champions' display of enthusiasm and strong believe in the success of the innovation. A behaviour that Howell et al (2005) in an earlier study identified as being prototypical of champions, and for which they provide a measure consisting of six sub-behaviours (enthusiastically promotes the innovation's advantages, expresses strong conviction about the innovation, expresses confidence in what the innovation can do, shows optimism about the success of the innovation, points out reasons why the innovation will succeed, keeps pushing enthusiastically). We identified specific connections between this particular champion behaviour and firms' willingness to participate in the innovation project. We therefore propose:
Proposition 1. Champions' expression of enthusiasm and confidence about the success of the innovation positively influences the allocation of resources to the innovation project.

Further, the case study data suggest that the positive influence of champion behaviour on firms' willingness to allocate resources is explained by positive expectations among firms of the future speed with which the innovation would be adopted by clients. In existing literature (Brancheau and Wetherbe, 1990; Rogers, 2003), the speed with which an innovation is adopted has been termed the 'rate of adoption'; measured by for example the number of clients or customers who adopt an innovation within a specified period, such as a year. In other words, we identified relationships between champions' enthusiasm and confidence in the innovation, firms' expectations of the rate of adoption, and firms' decisions to invest resources in the innovation projects. Consequently, we propose:

\section{Proposition 2. Champion expression of enthusiasm and confidence about the success of the innovation positively influences the allocation of resources to the innovation project by positively influencing firms' expectations of the rate of adoption.}

As a summary, Figure 2 displays the pattern that emerged from the case study data, and that provides an explanation for the effect of champion presence on resource allocation as found in previous research (and displayed in Figure 1).

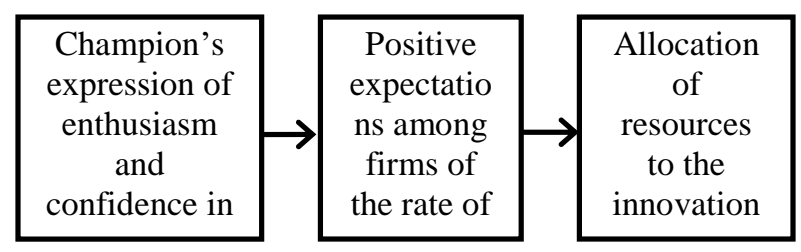

Figure 2: Model of the mechanism that emerged from the case study data and that provides an explanation for the effect displayed in Figure 1. 


\section{Discussion and Conclusion}

In this final section, we highlight the contributions made by this study to previous literature, and provide recommendations for future research. First, the insights provided by the case study into how champions might affect resource allocation, enrich the results from earlier studies. Here we refer to the studies by Chakrabarti (1974), Markham et al. (1991) and Markham (2000). These studies indicate that the presence of champions increases the likelihood of resource allocation. Relatively little is, however, known about how champions' presence exactly influence resource allocation (Markham, 1998; Schlapp et al., 2015). The present study provides two propositions that provide a potential and grounded explanation for the effect found in earlier studies. In doing so, the present study provides a step towards a deeper understanding of how champions positively influence the allocation of resources to innovation projects.

Second, on a more general level, the case study broadens the perspective on the effects that champions have in construction industry. The most studied champion effect in this field to date is that of champions on the innovativeness of construction projects (Tatum, 1984; Nam et al., 1991; Nam and Tatum, 1997; Barlow, 2000; Bossink, 2004; Dulaimi et al., 2005; Gambatese and Hallowell, 2011a). Only recently have construction management researchers begun to examine other effects. Here, we can refer to research on the effects of champions on the extent to which construction innovations diffuse (Gambatese and Hallowell, 2011b), on the social outcome of Percent for Art projects (McCabe et al., 2011) and on the performance of technology development projects (Caerteling et al., 2009). By illustrating how champions might affect the willingness of firms to allocate resources to an innovation project, this study adds a new dimension to the debate on the influence of champions in the construction industry.

At least two directions for future research can be identified. First, future research may shed light on the validity of the two propositions provided by the present study. Such research is of value since the case study method is a good method for developing grounded propositions, but to subsequently test the validity of such propositions a more quantitative research approach is recommended. For such a study, we recommend the use of existing measures of the champion behaviour construct and the rate of adoption construct (both constructs are displayed in Figure 2), as provided by Howell et al. (2005) respectively Brancheau and Wetherbe (1990). Second, future research may provide an answer to another question that follows from the study's findings. The current study provides a potential explanation for how champions' presence affects the allocation of resources to innovation projects. Champions' expression of enthusiasm and confidence about the success of the innovation has a key role in this explanation. Future research could explore whether this specific champion behaviour may also provide an explanation for other champion effects as reported in previous literature (see Table 1 and 2 for examples of such champion effects).

Overall, we conclude with the comment that many, if not most, innovations would not have existed if one or more firms had not invested resources in the development of the innovation. The value of the present study lies in its exploration of champions' capacity to make firms do so.

\section{References}

Andersson, L. M. \& Bateman, T. S. (2000) Individual environmental initiative: Championing natural environmental issues in us business organizations. Academy of Management Journal, 43(4), 548-70.

Barlow, J. (2000) Innovation and learning in complex offshore construction projects. Research Policy, 29(7-8), 973-89.

Blindenbach-Driessen, F., van Dalen, J. \& van den Ende, J. (2010) Subjective performance assessment of innovation projects. Journal of Product Innovation Management, 27(4), 572-92.

Boersma (1994) Predevelopment in technology-critical firms. Eindhoven University of Technology.

Bosch-Sijtsema, P. M. \& Postma, T. J. B. M. (2009) Cooperative innovation projects: Capabilities and governance mechanisms. Journal of Product Innovation Management, 26(1), 58-70.

Bossink, B. A. G. (2004) Managing drivers of innovation in construction networks. Journal of Construction Engineering and Management, 130(3), 337-45. 
Brancheau, J. C. \& Wetherbe, J. C. (1990) The adoption of spreadsheet software: Testing innovation diffusion theory in the context of end-user computing. Information Systems Research, 1(2), 115-43.

Caerteling, J. S., Halman, J. I. M., Song, M. \& Doree, A. G. (2009) Impact of government and corporate strategy on the performance of technology projects in road construction. Journal of Construction Engineering and Management, 135(11), 1211-21.

Chakrabarti, A. K. (1974) The role of champion in product innovation. California Management Review, 17(2), 58-62.

Day, D. L. (1994) Raising radicals: Different processes for championing innovative corporate ventures. Organization Science, 5(2), 148-72.

Devaney, M. (1991) Risk, commitment, and project abandonment. Journal of Business Ethics, 20(2), 157-59.

Dubois, A. \& Gadde, L. E. (2002) The construction industry as a loosely coupled system: Implications for productivity and innovation. Construction Management and Economics, 20(7), 621-31.

Dulaimi, M. F., Nepal, M. P. \& Park, M. (2005) A hierarchical structural model of assessing innovation and project performance. Construction Management and Economics, 23(6), 565-77.

Eisenhardt, K. M. (1989) Building theories from casestudy research. Academy of Management Review, 14(4), 532-50.

Gambatese, J. A. \& Hallowell, M. (2011a) Enabling and measuring innovation in the construction industry. Construction Management and Economics, 29(6), 553-67.

Gambatese, J. A. \& Hallowell, M. (2011b) Factors that influence the development and diffusion of technical innovations in the construction industry. Construction Management and Economics, 29(5), 507-17.

Herazo, B. \& Lizarralde, G. (2015) The influence of green building certifications in collaboration and innovation processes. Construction Management and Economics, 33(4), 279-98.

Hofman, E., Voordijk, H. \& Halman, J. (2009) Matching supply networks to a modular product architecture in the house-building industry. Building Research and Information, 37(1), 31-42.

Howell, J. M. \& Boies, K. (2004) Champions of technological innovation: The influence of contextual knowledge, role orientation, idea generation, and idea promotion on champion emergence. Leadership Quarterly, 15(1), 123-43.

Howell, J. M. \& Higgins, C. A. (1990) Champions of technological innovation. Administrative Science Quarterly, 35(2), 317-41.
Howell, J. M. \& Shea, C. M. (2001) Individual differences, environmental scanning, innovation framing, and champion behavior: Key predictors of project performance. Journal of Product Innovation Management, 18(1), 15-27.

Howell, J. M. \& Shea, C. M. (2006) Effects of champion behavior, team potency, and external communication activities on predicting team performance. Group \& Organization Management, 31(2), 180-211.

Howell, J. M., Shea, C. M. \& Higgins, C. A. (2005) Champions of product innovations: Defining, developing, and validating a measure of champion behavior. Journal of Business Venturing, 20(5), 64161.

Leiringer, R. \& Cardellino, P. (2008) Tales of the expected: Investigating the rhetorical strategies of innovation champions. Construction Management and Economics, 26(10), 1043-54.

Lichtenthaler, U. \& Ernst, H. (2009) The role of champions in the external commercialization of knowledge. Journal of Product Innovation Management, 26(4), 371-87.

Markham, S. K. (1998) A longitudinal examination of how champions influence others to support their projects. Journal of Product Innovation Management, 15(6), 490-504.

Markham, S. K. (2000) Corporate championing and antagonism as forms of political behavior: An r\&d perspective. Organization Science, 11(4), 429-47.

Markham, S. K., Green, S. G. \& Basu, R. (1991) Champions and antagonists: Relationships with $\mathrm{r} \& \mathrm{~d}$ project characteristics and management. Journal of Engineering and Technology Management, 8(3-4), 217-42.

Markham, S. K. \& Griffin, A. (1998) The breakfast of champions: Associations between champions and product development environments, practices and performance. Journal of Product Innovation Management, 15(5), 436-54.

McCabe, A., Parker, R. \& Brown, K. (2011) Social outcomes in the construction industry: The case of the western australian 'percent for art' policy. Construction Management and Economics, 29(9), 929-41.

Miozzo, M. \& Dewick, P. (2004) Networks and innovation in european construction: Benefits from inter-organisational cooperation in a fragmented industry. International Journal of Technology Management, 27(1), 68-92.

Nam, C. H., Gasiorowski, J. G. \& Tatum, C. B. (1991) Microlevel study of integration in high-strength concrete innovation. Journal of Construction Engineering and Management, 117(2), 294-309. 
Nam, C. H. \& Tatum, C. B. (1997) Leaders and champions for construction innovation. Construction Management and Economics, 15, 259-70.

Rogers, E. M. (2003) Diffusion of innovations. New York, Free Press.

Rothwell, R., Freeman, C., Horlsey, A., Jervis, V. T. P., Robertson, A. B. \& Townsend, J. (1974) Sappho updated - project sappho phase ii. Research Policy, 3(3), 258-91.

Royer, I. (2003) Why bad project are so bad to kill. Harvard Business Review, 81(2), 48-56.

Rutten, M. E. J., Dorée, A. G. \& Halman, J. I. M. (2009) Innovation and interorganizational cooperation: A synthesis of literature. Construction Innovation, 9(3), 285-97.

Schilling, M. A. (2010) Strategic management of technological innovation. Boston, McGraw Hill.

Schlapp, J., Oraiopoulos, N. \& Mak, V. (2015) Resource allocation decisions under imperfect evaluation and organizational dynamics. Management Science, 61(9), 2139-59.

Schön, D. A. (1963) Champions for radical new innovations. Harvard Business Review, 41, 77-86.

Sergeeva, N. (2014) Understanding of labelling and sustaining of innovation in construction: A sensemaking perspective. Engineering Project Organization Journal, 4(1), 31-43.

Shibeika, A. \& Harty, C. (2015) Diffusion of digital innovation in construction: A case study of a uk engineering firm. Construction Management and Economics, 33(5-6), 453-66.

Tatum, C. B. (1984) What prompts construction innovation? Journal of Construction Engineering and Management, 110(3), 311-23.

Toole, T. M., Hallowell, M. \& Chinowsky, P. (2013) A tool for enhancing innovation in construction organizations. Engineering Project Organization Journal, 3(1), 32-50.

Walter, A., Parboteeah, K. P., Riesenhuber, F. \& Hoegl, M. (2011) Championship behaviors and innovations success: An empirical investigation of university spin-offs. Journal of Product Innovation Management, 28(4), 586-98.

Yin, R. K. (2014) Case study research: Design and methods. Thousands Oaks, USA, SAGE. 